\title{
Effects of affinity to the Mediterranean Diet pattern along with breastfeeding on childhood asthma, inflammatory and recurrent diseases in an intervention study
}

\author{
Fernando Calatayud-Sáez ${ }^{1}$, BLANCA CALATAYUD ${ }^{2}$, Ana Calatayud-Moscoso del Prado ${ }^{3}$, \\ Mónica Luque-Navas ${ }^{3}$, JOSE G FERNANDEZ-PACHECOํ, and Francisco Rivas-Ruiz ${ }^{4}$ \\ ${ }^{1}$ Universidad de Castilla-La Mancha - Campus de Ciudad Real \\ ${ }^{2}$ private consulting \\ ${ }^{3}$ Hospital General Universitario de Ciudad Real \\ ${ }^{4}$ Marbella International University Centre
}

November 27, 2020

\begin{abstract}
Introduction: There is an increasing amount of data relating the dietetic pattern to health variables, although data concerning the child population are scarce. The aim of the study is to assess the effects of affinity to the Traditional Mediterranean Diet (TMD) pattern, together with breastfeeding, on the incidence of childhood asthma and inflammatory and recurrent diseases in children under two years of age. Methods: Quasi-experimental intervention study, where breastfeeding was promoted and following the TMD pattern was offered. The incidence of morbidity was evaluated and correlated with the dietary patterns which were followed. According to their adhesion to the TMD-Breastfed Test patients were classified into two groups: Group-1 (greater affinity) and Group-2 (lower affinity). Results: The score of the TMD-Breastfed Test was optimal in group-1 and good in group-2. It shows a marked reduction in both consultation groups "on request" compared with "planned", with low morbidity and low use of antibiotics. The incidence of infectious diseases and bacterial complications shows a clinically relevant difference between both groups. The incidence of childhood asthma was greater in group-2, with less adherence to breastfeeding. Conclusions: In these cohorts of breastfed patients with good adherence to TMD patterns, there was evidence of a low incidence of infectious diseases and childhood asthma, more pronounced in the breastfed group. Adapted milk and other foodstuffs of animal origin have been linked to being able to cause inflammatory and recurrent diseases, as their dietary limitations have contributed to decreasing morbidity.
\end{abstract}

\section{Title page}

\section{Original article. Title:}

Effects of affinity to the Mediterranean Diet pattern along with breastfeeding on childhood asthma, inflammatory and recurrent diseases in an intervention study

\section{Authors}

Calatayud-Sáez $\mathrm{FM}^{1}$, Calatayud B ${ }^{2}$, Luque $\mathrm{M}^{3}$, Calatayud A ${ }^{4}$, Gallego $\mathrm{JG}^{5}$, Rivas-Ruiz $\mathrm{F}^{6}$.

1 Pediatrician at the Child and Adolescent Clinic "La Palma". Address, telephone number and email: C/ Palma 17, bajo A, 13001 Ciudad Real, Spain. Telephone: +34 626612313. E-mail:altayud@gmail.com² Nutritionist at the Child and Adolescent Clinic "La Palma". Address telephone number and email: C/ Palma 17, bajo A, 13001 Ciudad Real, Spain. Telephone: +34 627524206. E-mail:blanca.calatayud@gmail.com 
${ }^{3}$ Nutritionits at the Child and Adolescent Clinic "La Palma". Address, telephone number and email: C/ Palma 17, bajo A, 13001 Ciudad Real, Spain. Telephone: +34 616362526. E-mail:monicaluque0208@gmail.com

${ }^{4}$ Nurse and nutritionist trainee at Child and Adolescent Clinic "La Palma". Address, telephone number and email: C/ Palma 17, bajo A, 13001 Ciudad Real, Spain. Telephone: +34 639993418. Email:anacalatayud94@gmail.com

${ }^{5}$ Family doctor at Health Center No. 1 of Ciudad Real. Plaza de la Provincia n ${ }^{0}$ 5, $3^{0}$ A. 13001, Ciudad Real, Spain. E-Mail:jggallegof@gmail.com

${ }^{6}$ Research unit.Costa del Sol Health Agency. Marbella (Málaga), Spain. E-mail:frivasr@hcs.es

Clinic and department completing the study: Child and Adolescent Clinic "La Palma", C/ Palma 17, bajo A, Ciudad Real, 13001. Castilla la Mancha. Spain.

Author for correspondence : Fernando M. Calatayud-Sáez. Child and Adolescent Clinic "La Palma". C/ Palma 17 Bajo A, 13001 Ciudad Real, Spain. Telephone:+34626612313 E-mail:altayud@gmail.com, Twitter: @pednutricional

\section{The project's financial support}

Grant from the Mutua Madrileña Foundation (FMM) for the study of childhood asthma in relation which the Traditional Mediterranean diet in 2016.

Grant from the Spanish Association of Paediatrics for primary care (AEPap), to carry out this project, in 2017.

Word count: 2349 Number of tables: 5 Number of figures: 1

The authors declare no potential conflicts of interest with respect to research, authorship and/or publication of this article.

This work has not been funded by any organization and there is no potential conflict of interest which could introduce some bias in the content of the presentation, or has any commercial relationship that might be perceived by participants as such conflict. Nor has it been published or is under consideration for publication in any other journal.

Protection of human subjects and animals. The authors state that the procedures followed were in accordance with the regulations of the Ethics Committee for Clinical Research responsibly and in accordance with the World Medical Association and the Declaration of Helsinki.

Confidentiality of data. The authors declare that they have followed the protocol of the workplace in the publication of patient data and all patients included in the study have received sufficient information and gave written informed consent to participate in this study.

Right to privacy and informed consent. The authors declare that there is no patient data displayed on this article.

Short title: Mediterranean diet and inflammatory diseases

Key words: Inflammatory disease; recurrent illness; childhood asthma; Mediterranean diet; dietary intervention; dietary awareness.

\section{Hosted file}

Main document.pdf available at https://authorea.com/users/379219/articles/495505-effects-ofaffinity-to-the-mediterranean-diet-pattern-along-with-breastfeeding-on-childhood-asthmainflammatory-and-recurrent-diseases-in-an-intervention-study

\section{Hosted file}


Tables.pdf available at https://authorea.com/users/379219/articles/495505-effects-ofaffinity-to-the-mediterranean-diet-pattern-along-with-breastfeeding-on-childhood-asthmainflammatory-and-recurrent-diseases-in-an-intervention-study

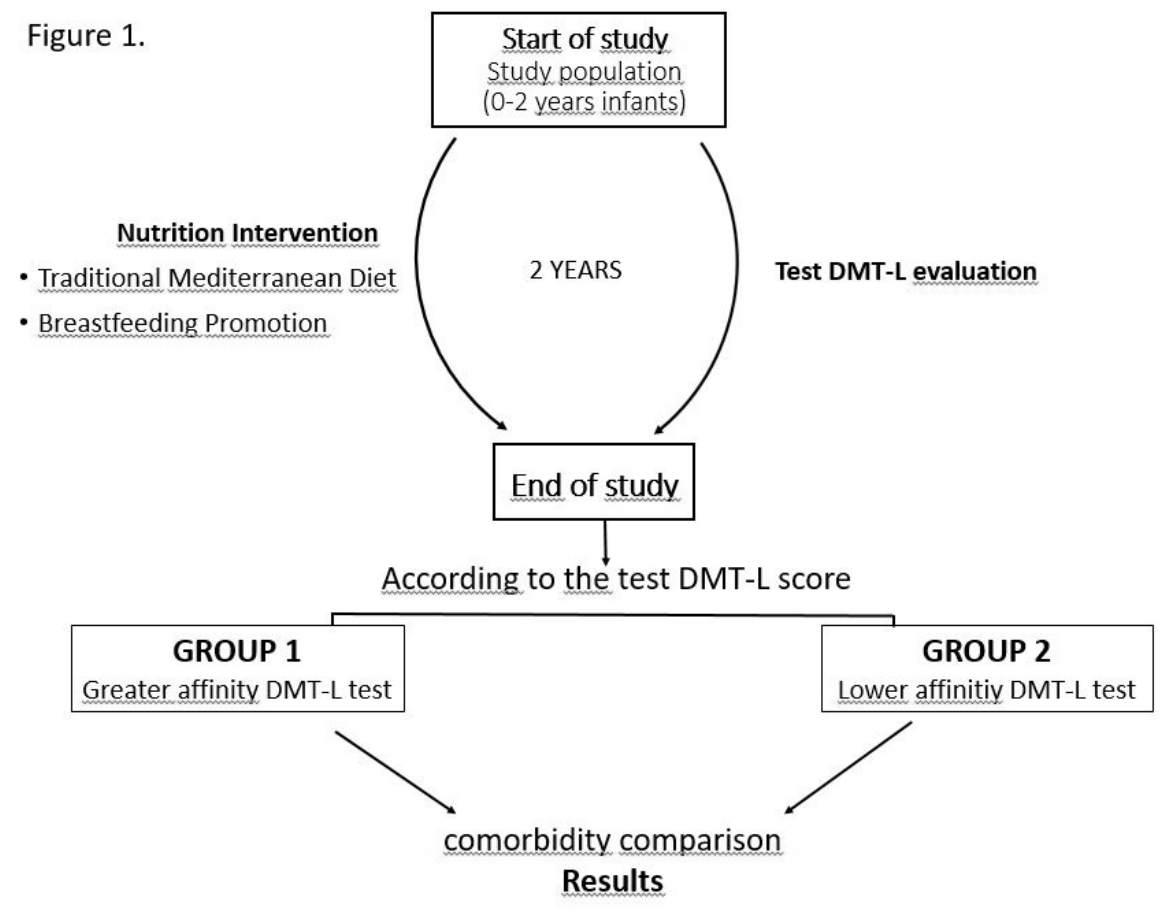

